\title{
KNOWLEDGE MANAGEMENT IN SMALL AND MEDIUM-SIZED ENTERPRISES
}

\author{
Wladimir Bodrow \\ University of Applied Sciences Berlin, Germany.Email:w.bodrow@fhtw-berlin.de
}

\begin{abstract}
In this paper the attempt to consolidate the diversity in theoretical aspects of knowledge management in Europe starting from 2004 (CEN/ISSS 2004) is briefly presented. Conform to this context some original results are discussed as well. In the thereon following part diverse knowledge management tools and systems - mainly developed using Information and Communication Technology (ICT) - are introduced. After it the European road map for implementing the knowledge management is described. In addition some aspects of the application of KM in small and medium-sized enterprises will be considered.
\end{abstract}

Key words: Knowledge management, knowledge-oriented enterprise, small and mediumsized enterprises

\section{INTRODUCTION}

The past decade activities in the global business in general and those in small and medium-sized enterprises (SMEs) in European countries in particular mark a paradigm shift. According to Peter Drucker "...the basic economic resource is no longer capital, nor natural resources, nor labor. It is and will be knowledge." (Drucker 1993) This message has now reached not only global players such as IBM, Hewlett Packard, Siemens, Cisco, McKinsey and Toyota but also a long list of small and medium-sized companies.

All together they accept knowledge as the most important factor of their business processes. During the last ten years many of them have started to implement a number of projects and solutions to improve the exploitation of

Please use the following format when citing this chapter:

Bodrow, Wladimir, 2006, in International Federation for Information Processing (IFIP), Volume 207, Knowledge Enterprise: Intelligent Strategies In Product Design, Manufacturing, and Management, eds. K. Wang, Kovacs G., Wozny M., Fang M., (Boston: Springer), pp. 41-53. 
company knowledge in a wide range of business areas. A more thorough examination makes clear that until now there has not been one universal theory of knowledge management with a world wide acceptance by business and research institutions. In fact various concepts and approaches of knowledge management are currently in use in different European countries.

\section{STATE OF THE ART IN THEORY - KM MODELS}

Beginning with Ikujiro Nonaka and Hirotaka Takeuchi (Nonaka and Takeuchi 1995), Karl Erik Sveiby (Sveiby 1998) and other pioneers some dozens of knowledge management approaches were developed around the globe in the past decade. A part of them were implemented and approved in business practice worldwide. To name different knowledge managements approaches developed in Europe, here is a non complete list:

- Building blocks for knowledge management (Probst et al. 1999)

- Model of integrative knowledge managements (Reinhardt and Pawlowski 1997)

- Four steps toward knowledge management (Schüppel 1996)

- Lifecycle model of knowledge management (Rehäuser and Krcmar 1996)

- Company knowledge market model (North 2005)

- Process oriented model of Fraunhofer IPK (Mertins et al. 2003)

- Process-oriented knowledge management strategy (Maier 2004)

Brief consideration on these and other established approaches developed in the USA, Japan and other non-European countries shows a number of partially and completely agreeing aspects. This was the background for our investigation toward a common approach in knowledge management (Bodrow and Fuchs-Kittowski 2004, Fuchs-Kittowski and Bodrow 2004). The empirical analysis of 18 known approaches shows that the most important aspect of knowledge management actually is the use of knowledge. After the first presentation of the achieved results we extended the number of approaches to be investigated. This extension did not change the main tendencies observed before. Researchers and practitioners around the globe consider knowledge using ("application", "execution", "processing", "utilization" were used by different authors as well) as the most essential activity within knowledge management. On the second position with only a very small difference they see the sharing ("distribution", "dissemination", "communication", "exchange") of knowledge. The third and fourth place is occupied by the generation ("creation", "production", "discovery") and integration ("linkage", "interpretation", "adaptation") of knowledge into the structure of the resources available respectively. The identification 
("filtering", "selecting") as well as the acquisition ("procuring", "collecting", "importing", "assimilating") and development ("derivation") achieved fifth places within the list of the 18 activities selected for the analysis. The storage ("saving", "retaining") of knowledge is on the sixth position. The most surprising point was the fact that all activities defined by Nonaka and Takeuchi - socialization, internalization, combination and externalization hold their positions at the end of the hierarchy of activities in the analyzed knowledge management approaches. This is explainable by the knowledge management's strong orientation onto the exploitation of knowledge in enterprises and on the market likewise. These additional results derived from the investigation:

- This kind of empirical investigation can be considered a strategy toward a common or general approach to knowledge management. Further diversification of the existing approaches with their specialization according to the specifics of knowledge or (business) application is regarded as contra productive.

- The methodology we selected for our investigation delivered impulses for the development of a knowledge management ontology. Based on an empirical analysis of the different approaches it is possible to derive (or to sort out) the best accepted one and define its attributes and structure. Broad acceptance of an ontology build this way is the only factor indicating its quality!

- In the same investigation we changed the subject matter and analyzed the possibilities for building a knowledge ontology. Our conclusion is that the preferable basis to build such an ontology in general or in particular fields is an analysis of the activities. It allows to consolidate different perspectives and approaches and to establish a so-called activity ontology. For a correct analysis and satisfactory results in this field the investigation should be based on a well-founded linguistic knowledge. This is obligatory since the diversity of all the existing definitions has primarily been made by experts in special application areas. These definitions have to be communicated adequately among researchers and practitioners. While most research projects teams are mainly content or topic oriented they lack expertise in linguistic skills, which is the basis for a proper definition. As mentioned before the appropriate knowledge distribution and communication is one of the most important activities within knowledge management.

The importance of the ideas and results discussed were underlined by the workshop agreement published as a result of CEN/ISSS workshop in Madrid (CEN/ISSS 2004). Materials of this workshop with the title "European guide to good practice in knowledge management" (in following European guide) contain five parts: 
1. KM Framework

2. Culture and KM

3. Implementing KM in Small and Medium-Sized Enterprises

4. Measuring KM

5. KM Terminology

and represent the state of the art in European research and practice in knowledge management. More than 100 researchers and practitioners from Europe, America and Asia participated in developing this European knowledge management agreement. Following the main ideas of this guide (except KM Terminology) will be briefly presented and discussed.

\section{KM FRAMEWORK}

The KM Framework proposes three layers for knowledge management: a) The first and most important layer of the presented concept is oriented on business processes including all participants and their knowledge.

b) The second layer defines the core knowledge activities used by organizations in Europe - identification, creation, storage, sharing and use of knowledge.

c) The third layer represents the enabler of knowledge management. It consists of personal and organizational knowledge capabilities.

The only difference between this framework and our results (Bodrow and Fuchs-Kittowski 2004) is the absence of "storage" among the first five knowledge activities in our register. Instead of it we observed that the "integration of knowledge" into the existing structure is considered as more important. Possible explanation to these discrepancies can have semantic background. The mentioned before well-founded linguistic analysis is the way to clarify the situation.

\section{CORPORATE CULTURE IS THE MOST SIGNIFICANT FACTOR OF KM}

The survey of German TOP 1000 and European TOP 200 companies made by Fraunhofer IPK Berlin (Mertins et al. 2003) illustrated that the first five decisive factors of a successful knowledge management are corporate culture $(47,1 \%)$, structural factors/external conditions $(29,8 \%)$, information technology (27,9\%), staff motivation and qualification $(27,9 \%)$ and promotion by top management $(26,9 \%)$. The importance of cultural aspects and their influence on a successful knowledge management was also confirmed in other surveys and projects (KPMG 2001, ME Survey 2003). 
Starting from this crucial aspect the following factors of enterprise culture were defined and described in the European guide (CEN/ISSS 2004):

1 . The relationship between knowledge and culture. In this part of the guide the barriers to a successful knowledge management are listed and the differences between traditional and knowledge-aware organizations are presented.

2. Individuals, groups and organizations. Beforehand authors defined enterprise culture and provided a short list of the corresponding facets. Subsequently they concentrated the examination on the different participants of culture, starting from a single person till the whole organization. Here different identities in respect to individual, functional, organizational or geographical characteristics of communities within and among enterprises are presented. Corporate culture acts as a mediator for the communication between the personal and organizational knowledge.

3. Trust and motivation. This chapter is devoted to the most important aspects of a successful knowledge management in the enterprise: trust, motivation and leadership. The results of the LexisNexis survey published in 2004 (LexisNexis 2004) are interesting in this context. They underline that $49 \%$ of all enterprises prefer humanists and social scientists and/or practitioners with a soft skill (educational) background for their knowledge manager position. Consequently various diplomas of Art are preferred to MBA graduates (only occupying the second place by $38 \%$ ). A technical background, including computing, stands last in this line. The practice and development of actual knowledge management in Europe is looking for generalists, who can communicate all aspects of knowledge management and motivate the employees in the enterprise. According to the same survey $72 \%$ of employees are motivated by their own working achievements whereas only $10 \%$ are interested primarily in monetary rewards. The significant change of this trend from 2003 to 2004 emphasizes on the importance of cultural aspects for a successful knowledge management.

4. Competencies, learning and reflection. The crucial point of this chapter is a view on the process of knowledge creation in an enterprise. Authors subdivided the knowledge creation process into four parts: empathizing, articulating, connecting and embodying. The presented iterative cycle of knowledge creation differs significantly from the one by Nonaka and Takeuchi. The results of recent surveys (ME 2003, LexisNexis 2004) document a change in the knowledge generation as well. Actually they dealt with another object of change - the changing of the learning processes. The most important source of knowledge for the employee is the practical skill gained from team work. Moreover the majority of knowledge managers $(85 \%)$ refuse to use books as an efficient source to improve their knowledge and prefer for that reason learning-by-doing directly in the project. 
5. Tools to manage relationships that drive learning processes. The activities in this area have to follow the conviction that corporate-wide communication is the only basis for an efficiently organized knowledge exchange and production process. Correspondingly in the guide both formal and informal communities were suggested as important tools to improve the communication. At the beginning as well as accompanying knowledge management project activities, observation and questioning are considered mandatory. The knowledge audit is the proposed tool to identify the situation beforehand and during the project. Coaching and mentoring were accounted as well known and widely-established tools for knowledge transfer. Furthermore the authors examine the narrative, conversation and dialogue as additional possibilities for the knowledge exchange. In the guide the technology (ICT) is accepted as an enabler to connect people and support their communication a better way.

\section{STATE OF THE ART IN TECHNOLOGY - KM SYSTEMS}

The general goal of knowledge management is to provide each and every decision maker in all decision relevant areas with the right knowledge (according to his/her level of expertise) in the right form and quality, and at the right time and place. This goal is part of the common managerial vision in every single enterprise. A particular knowledge management system does not a priori imply information and/or communication technology. Today's wide consensus on ICT as an enabler to knowledge management has changed this position significantly. The number of approaches named before was implemented in various ICT-based knowledge management systems. They use different well-known and established information processing systems and technologies appropriate for the particular application. These systems support the already mentioned efficient providing of the decision makers with the relevant information of different kinds. Here is an incomplete list of technologies and systems in use: Groupware, Workflow, Document management system, Content management systems, Knowledge based or expert systems, Intelligent software agents, Data warehouse, Business intelligent systems, Collaboration systems, E-Learning systems, Customer relationship management, Intranet, Knowledge and enterprise portals, Human resources management.

With the help of these technologies various systems to support enterprise wide knowledge management were developed. They have many names from "knowledge management software" through "knowledge management support system" till "knowledge warehouse". A long structured list of ICT- 
based knowledge management tools is offered for instance by Ronald Maier (Maier 2004). In the analysis of the foundations of knowledge management systems Maier (Maier 2004, p.79) attempts to formulate a general definition for such systems. This seems a complicated endeavor just because of the variety of the existing views and definitions on knowledge, management and knowledge management.

In the investigation of knowledge management tools made by the research group of the Fraunhofer IPK (a knowledge management competence center in Germany) another standpoint is preferred (Mertins et al. 2003). Diverse established solutions are examined here in respect to the defined four core activities of knowledge management - create knowledge, store knowledge, distribute knowledge and use or apply knowledge. The investigated knowledge management tools are subdivided into eight groups:

1. Search engines/categorization tools/ intelligent agents.

According to Fraunhofer IPK, the tools in this group primarily assist the application of knowledge. Some other aspects could be added to this position: a) search engines can support the knowledge creation by providing the user with knowledge related to the topic from different perspectives. b) search engines and intelligent agents support the knowledge sharing and dissemination (target oriented knowledge distribution) as well. Among international providers like Alexa (www.alexa.com) or Magnifi (www.magnifi.com) listed in the paper one can find German products i.e. Knowledge Miner from USU AG (www.usu.de) and SchemaText from SchemaGmbH (www.schema.de).

\section{Portals}

Following Fraunhofer IPK, portals - including knowledge-, enterprise-, and information portals - are useful to store, distribute and apply knowledge. Apart from the RetrievalWare, Excalibur Technologies's tool (www.excalib.com), also AskMe offered by AskMe Corporation (www.askmecorp.com) is listed. The authors underscore that the most complete KM suites are implemented as portals. Consequently the creation of knowledge can be considered as an activity covered by portals as well.

3. Visualizing tools

These tools are to promote the presentation of knowledge adequately to the particular tasks and the individual user capabilities (e.g. skill and experience). This way they support the practical application of the knowledge presented. The German product Think Tool from Think Tools AG (www.thinktools.com) is listed here on the side of IBM tool KnowledgeX (www.ibm.com) and Eureka from InXight Software (www.inxight.com).

4. Skill management

Another kind of visualization is covered by skill management tools. They point to the location and quality of knowledge available in the enterprise. 
Different solutions like knowledge maps, yellow pages, competence maps or skill maps can be realized using tools from this group. Some European products - Yellow Pages from altavier GmbH (www.altavier.de) - is listed here besides for instance Competence Manager from HR Hub.com (www.hrhub.com) or ScillView Enterprise from SkillView Technologies Inc. (www.skillview.com). These tools and the corresponding solutions are primarily responsible for the storage and distribution of knowledge in the enterprise.

5. Complete KM suites

Starting from the fact that the development of a complete KM suite is the goal of every provider, many European companies today offer a number of those complete tools. In the list presented one can find infonea from Comma-Soft AG (www.comma-soft.com), Knowledge Warehouse from SAP (www.sap.com), Business Process Management tools from IDS Scheer AG (www.ids-scheer.de) on the side of Aungate's suite from Aungate (www.aungate.com), Livelink from OpenText (www.opentext.com) or Hummingbird Enterprise KM from Hummingbird (www.hummingbird.com). All these and other listed tools support a complete life cycle of knowledge in the business solution.

6. Toolkits for developing individual solutions

These toolkits serve the development of individual solutions. Like the complete KM suites they cover all four activities within knowledge management: creation, storage, distribution and application of knowledge. Since their individuality a high effort is necessary to fit such tools to the company's individual needs. DynaSight from arcplan (www.arcplan.com) is listed here on the side of StoryServer from Vignette (www.vignette.com), Digital Dashboard from Microsoft (www.microsoft.com) and BackWeb solution of BackWeb (www.backweb.com).

7. Learn and teach

The first and foremost focus of MediaNaut from Chronomedia $\mathrm{GmbH}$ (www.medianaut.com), the only German tool in this group, is the creation of knowledge. Founded on an adequate presentation of the stored knowledge user obtains an appropriate assistance in learning and creating new knowledge.

8. Virtual teams/collaboration

The two tools in this group (eRoom from EMC Documentum (www.documentum.com) and HyperKnowledge from HyperKnowledge (www.hyperknowledge.com) provide a special support in the creation, storage and distribution of knowledge in the enterprise. Discussion groups and virtual teams primarily implemented within these tools are a result of the strong orientation on communication of these tools.

The main outcome of the investigation made by Fraunhofer IPK is the general adaptation of the knowledge management tools to the employees and their tasks within business processes. 


\section{APPLICATION OF KM IN SMES}

The roadmap for the development and implementation of knowledge management solutions in the business praxis is summarized in the third chapter of the European guide (CEN/ESSS 2004). Following the European guide the general scheme for the implementation of knowledge management in small and medium-sized enterprises consists of five phases:

A Setting up a knowledge management project

In this phase the management defines and communicates in detail the mission, vision, strategy and the aims for the knowledge management project to every employee in the enterprise.

\section{$B$ Assessment}

The activities in this phase support the understanding of the actual state and strategy of the knowledge management within the enterprise. The management is advised to apply an assessment tool for a better understanding. The authors give a short description of five assessment tools including diagnostic tools, knowledge audits and knowledge management audits.

\section{Development}

The main results of this phase are a) a well defined concept for one kind of knowledge management solution and b) a suggestion for the tools and technologies to be applied. The tool classification according to their applicability presented in the same chapter involves more than just ICTbased tools as in both previously referred investigations. This classification is focused on five previously defined knowledge management activities.

\section{Implementation}

Three factors were considered as crucial for the implementation of KM solutions - people, time and budgetary control. The authors formulate and give a detailed description of seven action steps within the implementation process. Different time restrictions with respect to the milestones and corresponding communicational facets were defined as well. As an important point of the implementation the adherence to a time limit was pointed out.

\section{E Evaluation/Sustainability}

In sum knowledge management's goal is to establish itself as an integral part of the business process. This way knowledge management becomes sustainable in the enterprise. The success of the project can be identified and measured based on it. A useful approach for a systematic evaluation of all stages of the project is the "lessons learned".

The milestones defined accordingly support an easy realization of each phase of the project implementation described. 


\section{MEASURING KM}

Since knowledge has no originally quantitative attributes like other resources used in business processes, it is impossible to measure it directly in countable units. On the other hand knowledge has a value and consequently is the part of different business activities. A remarkable aspect is that the value of the same knowledge can vary from one situation to another and therefore this value is strong dependent on each particular business case. Outgoing from these ideas it has to be necessary to measure the knowledge (and following the knowledge management) to know and/or to improve the return of investment and other indicators of KM activities.

According to the European guide there are five dimensions directly related to intellectual capital (IC) for adding value through knowledge management:

1. Financial focus

2. Innovation focus

3. Process focus

4. Customer (client) focus

5. Human (employee) focus

On the basis of these dimensions three different types of intellectual capital are defined: Human capital, Structural capital and Customer capital. From this perspective the measurement of KM is the basis for the quantity of corporate intellectual capital. In that way the enterprise can control the development of IC. Different strategies and technologies to measure KM in the enterprise are also described in the European guide. In the same part several approaches for the measurement of the intangible assets are presented and partly described. Additionally the authors give a recommendation for the direct and indirect measures of KM. Some aspects of the German project in this area are the topic of the next chapter.

\section{KM PRACTICE IN SMES}

"Wissensbilanz - Made in Germany" (www.akwissensbilanz.org) is the current project in regard to measure knowledge management in small and medium-sized enterprises in Germany. The German expression Wissensbilanz (literally knowledge balance sheet) can rather be referred to as "intellectual capital report", "intellectual capital accounts" or "intellectual capital statement". It includes the evaluation of qualitative and quantitative outcomes of knowledge based and knowledge oriented business activities in a particular enterprise. Because of the unclear separation between knowledge 
and intangible assets as well as intellectual capital the literal transcription "knowledge balance sheet" is used in this chapter. The legal regulations for such a knowledge balance sheet is defined in the German Accounting Standards DRS 12 published in 2002 (www.drsc.de) and in the International Accounting Standards IAS from 2005 (www.iasb.org). According to DRS 12 enterprises can refer to different facets of intellectual capital in their accounting: human capital, customer capital, supplier capital, investor capital, process capital, location capital and innovation capital. To include the intangible asset into the accounting IAS (chapter 38) defines four critical attributes: identifiability, control, potential economic benefits and reliable acquisition and production costs. Examples of intangible assets listed in IAS include among others computer software, patents, copyrights, licenses, customer lists and marketing rights. "Wissensbilanz - Made in Germany" is part of a governmentally supported contest "Fit für den Wissenswettbewerb" (literally fit for knowledge competition) and initiative "Wissensmedia" (literally knowledge media). It represents the possible ways to establish knowledge management in a wide business practice. The roots of an intellectual capital analysis are to be found in pioneer publications of Scandinavian researchers Karl-Erik Sveiby (Sveiby1998), Leif Edvinsson (Edvinsson 1997). There are numerous approaches for knowledge evaluation based on monetary and non-monetary indicators (Bodrow and Bergmann 2003, Mertins et al. 2005, North 2005 p 219). They use the concept of Balanced Scorecard developed by Robert Kaplan and David Norton (Kaplan and Norton 1996) in various modifications. The idea to compose a regular balance sheet for corporate knowledge goes back to the Austrian Professor Günter Koch. Such knowledge balance sheets can be downloaded from the site of Austrian Research Centers since 1999 (www.arcs.ac.au). Many Austrian Universities have published their knowledge balance sheets beginning from 2002 (e.g. www.donau-uni.ac.au). In 2007 the Austrian administration will publish the first profound knowledge balance sheet for the whole country. Both the results achieved and the experiences gathered by Austrian colleagues provide a basis for German and other international projects. The main aim of the project "Wissensbilanz - Made in Germany" is different from the Austrian concept. It concentrates on the dissemination of knowledge management skills and technologies in small and medium-sized enterprises. As a result of the activities in this project several knowledge balance sheets were published last year on the project's site (www.akwissensbilanz.org). Currently similar projects are in the process of realization in other European countries as well e. g. Switzerland and Denmark. On the groundwork of the outcome of these projects the management will be able to identify and represent the knowledge available in the enterprise (remember knowledge identification is one of the five 
activities in the European guide). As a result the management of the enterprise receives instruments to control the development of its corporate knowledge and consequently its knowledge management.

\section{OUTLOOK}

Management change in large as well as in small and medium-sized enterprises around the globe today is a result of the broad acceptance of knowledge as the main business resource and the formation of knowledge economy in general. The gathered experiences in this field will lead to a generalization from the different approaches of $\mathrm{KM}$ toward one single universal approach. Parallel to this generalization SMEs will continue to integrate knowledge management in their business processes. Such specific favorable conditions for knowledge management like flat hierarchies, less organizational boundaries, efficient, traditional and already established informal knowledge exchange, clearly defined volume and reliability of knowledge are definitely advantageous to establish a successful knowledge management.

\section{REFERENCES}

Bodrow W, Bergmann P (2003) Wissensbewertung in Unternehmen. Erich Schmidt Verlag, Berlin

Bodrow W, Fuchs-Kittowski K (2004) Wissensmanagement in Wirtschaft und Wissenschaft. Wissens chafts fors chung.

Jahrbuch 2004 (in print) CEN/ISSS Knowledge management workshop (2004) European guide to good practice in knowledge management. http://www.cenorm.be/cenorm/businessdomains/businessdomains/ isss/cwa/knowledge+management.asp, 9.2.2006

Drucker P (1993) A post-capitalist society. Econ, New York.

Edvinsson L (1997) Developing intellectual capital at Scandia. Long Range Planning, 30/6, pp 266-373

Fuchs-Kittowski K, Bodrow W (2004) Wissensmanagement für Wertschöpfung und Wissensschafung. In: Banse G, Reher EO (eds.) Fortschritte bei der Herausbildung der Allgemeinen Technologie. Sitzungsberichte der LeibnizSozietät Vol. 75, Verlag Irena Regener, Berlin, pp 81-104

Kaplan R, Norton D (1996) The Balanced Scorecard. Harvard Business School Press, Boston

KPMG (2001) Bedeutung und Entwicklung des multimediabasierten

Wissensmanagements in der mittelständischen Wirtschaft.

http://www.wissensmedia.de/studie kpmg.pdf, 9.2.2006 
LexisNexis (2004) Wissensmanagement in deutschen Unternehmen. http://www.lexisnexis.de/downloads/umfrage.pdf, 9.2.2006

Maier R (2004) Knowledge Management Systems. 2nd edn. Springer, Berlin Heidelberg New York

ME (2003) Wissensmanagement in deutschen Unternehmen. http://www.competencesite.de/wissensmanagement.nsf/0/497e577 2f05ee450c1256e7e002ca3a8? OpenDocument, 9.2.2006

Mertins K, Alwert K, Heisig P (eds) (2005) Wissensbilanzen-Intellektuelles Kapital erfolgreich nutzen und entwickeln. Springer, Berlin Heidelberg New York

Mertins K, Heisig P, Vorbeck J (eds) (2003) Knowledge management: concepts and best practices. 2nd. edn. Springer, Berlin Heidelberg New York

Nonaka I, Takeuchi H (1995) The knowledge creating company. Oxford University Press, Oxford

North K (2005) Wissensorientierte Unternehmensfürung. 4th edn. Gabler, Wiesbaden

Probst G, Raub S, Romhardt K (1999) Wissen Managen. 3d edn, Gabler, Wiesbaden

Reinhardt R, Pawlowsky P (1997) Wissensmanagement. In: Wieselhuber \& Partner (eds) Handbuch Lernende Organisation. Gabler, Wiesbaden

Rehäuser J, Krcmar H (1996) Wissensmanagement in Unternehmen. In Schreyögg G, Conrad P (Eds.) Managementforschung Vol.6 Wissensmanagement. Erich Schmidt Verlag, Berlin New York, pp 1-40

Schüppel J (1996) Wissensmanagement: organisatorisches Lernen im Spannungsfeld von Wissens- und Lernbarrieren. Gabler, Wiesbaden

Sveiby KE (1998) Wissenskapital -das unentdeckte Vermögen. Moderne Industrie, Landsberg (other publications at www.sveiby.com.au) 